\title{
Developing an intervention to support lung cancer patients and their clinicians when considering systemic anti-cancer therapy: pact study
}

\author{
Annmarie Nelson ${ }^{1 *}$, Stephanie Sivell ${ }^{1}$, Simon Noble ${ }^{1}$, Anthony Byrne ${ }^{1}$, Jason Lester ${ }^{2}$ \\ From 2nd Clinical Trials Methodology Conference: Methodology Matters \\ Edinburgh, UK. 18-19 November 2013
}

\section{Background}

Lung cancer patients may inappropriately receive systemic anti-cancer therapy (SACT) when they are close to end of life, despite evidence that early palliative intervention can led to less aggressive care and longer survival [1]. The National Confidential Enquiry into Patient Outcome and Death made the recommendation that acceptance of treatment/treatment decision should be made by the patient after they have been fully informed of the risks and benefits [2].

\section{Aims}

To identify the information and decision support needs of patients and to design an intervention to facilitate discussion of the risks and benefits of the available treatment options.

\section{Methods}

Observations of interactions at MDT meetings and patient-clinician consultations $(n=20-30)$ will identify how patients are allocated to treatment pathways, how treatment management options are presented to patients and the extent of patient involvement in treatment planning. Semi-structured face-to-face interviews with patients and clinicians will explore perceptions of the treatment management options, and attitudes and perceived involvement in treatment decisions. These data will be used to inform the design, development and subsequent evaluation of the intervention, including an appropriate theoretical basis.

'Marie Curie Palliative Care Research Centre, Cardiff University School of Medicine, Cardiff, UK

Full list of author information is available at the end of the article

\section{Results and conclusions}

Data collection will commence in the autumn of 2013. We anticipate the data to provide an insight into why lung cancer patients may receive SACT when palliative care may perhaps be more appropriate. The resulting intervention will be made available to patients and clinicians to provide information and support when considering uptake of SACT for lung cancer.

\section{Authors' details \\ 'Marie Curie Palliative Care Research Centre, Cardiff University School of Medicine, Cardiff, UK. ² Velindre NHS Trust, Cardiff, UK.}

Published: 29 November 2013

\section{References \\ 1. Temel, et al: NEJM 2010, 363:733-42. 2. NCEPOD. 2008.}

doi:10.1186/1745-6215-14-S1-P8

Cite this article as: Nelson et al:: Developing an intervention to support lung cancer patients and their clinicians when considering systemic anticancer therapy: pact study. Trials 2013 14(Suppl 1):P8.

Submit your next manuscript to BioMed Central and take full advantage of:

- Convenient online submission

- Thorough peer review

- No space constraints or color figure charges

- Immediate publication on acceptance

- Inclusion in PubMed, CAS, Scopus and Google Scholar

- Research which is freely available for redistribution 